\section{Argon laser photocoagulation for retinopathy of prematurity: long-term outcome}

LH Ospina, CJ Lyons, C Matsuba, J Jan and AQ McCormick

\section{Abstract}

Purpose To assess the visual, refractive, ocular structural, and neurodevelopmental outcome in a group of children who were screened, treated with laser photocoagulation for threshold retinopathy of prematurity (ROP), and followed up at our institution.

Methods The 21 survivors of a cohort of 23 children were recalled at the age of 5 years or more. They underwent a full ophthalmologic examination. A paediatric neurologist and/or developmental paediatrician performed a neurodevelopmental assessment and a neuropsychologist performed psychological testing.

Results A total of 30 eyes (71.4\%) had a bestcorrected visual acuity (BCVA) of 20/40 or better. In all, $26(62 \%)$ eyes were myopic; the overall mean spherical equivalent was $-4.95 \mathrm{D}$. No eye had Stage 4 findings and only one eye $(2.4 \%)$ progressed to stage 5 despite photocoagulation. In total, 14 patients $(66.6 \%)$ showed evidence of stereopsis. Strabismus was seen in six patients $(\mathbf{2 8 . 5 \% )}$ and nystagmus in three (14.3\%). Periventricular leukomalacia (PVL) was identified in five patients $(23.8 \%)$, cerebral palsy $(\mathrm{CP})$ in seven $(33.3 \%)$, and intraventricular haemorrhage (IVH) in $13(62 \%)$. Cerebral palsy and IVH associated strongly with visual acuity of less than $20 / 40(P=0.009$ and 0.047$)$. There was also a strong association between visual acuity of $20 / 40$ or above and a better cognitive outcome $(P=0.013)$.

Conclusions Retinal scarring and detachment are relatively rare causes of visual morbidity 5 years or more after laser treatment for threshold ROP, but the neurological sequelae of extreme prematurity and amblyopia remain important causes of impaired visual function. Eye (2005) 19, 1213-1218. doi:10.1038/sj.eye.6701729; published online 22 October 2004

Keywords: laser; outcome; prematurity; retinopathy

\section{Introduction}

Cryotherapy was shown to be beneficial for patients with threshold retinopathy of prematurity (ROP) by the Cryo ROP study. ${ }^{1-4}$ Since then, laser photocoagulation has largely replaced cryotherapy as the treatment of choice, with improved anatomical and visual outcomes. ${ }^{5-9}$ Laser photocoagulation is also thought to induce less myopia than cryotherapy. ${ }^{7,8,10-12}$ Nevertheless, ROP remains an important source of visual impairment in childhood and is one of the important treatable causes of blindness worldwide. ${ }^{13,14}$ In the United States and the developed world, ROP remains one of the three leading causes of paediatric blindness/severe visual disability. ${ }^{13}$ It is also an increasing problem in the developing world with the improving survival of low and very low birth weight infants. ${ }^{15}$

There is little information regarding the longterm visual outcome after laser treatment for ROP. We followed a cohort of patients for at least 5 years and wished to review their structural, refractive, visual, and neurodevelopmental outcome. Since posterior visual pathway factors related to neurological injury can affect vision in $\mathrm{ROP}^{16}$ we also wished to review and analyse their possible contribution to the final outcome in this group of patients.
Department of Ophthalmology, British Columbia Children's Hospital,

University of British

Columbia,

Vancouver, British

Columbia,

Canada

Correspondence: CJ Lyons, Department of Ophthalmology, British Columbia's Children's Hospital,

4480 Oak Street,

Vancouver, British

Columbia,

Canada V6H 3V4,

Tel: + 1604875 3117;

Fax: + 16048753561

E-mail: cjlyons@

telus.net

Received: 14 March 2004 Accepted in revised form: 13 July 2004 Published online: 22 October 2004

Financial interest: None 


\section{Materials and methods}

All the patients who underwent screening and subsequent treatment for ROP at our institution between March 1994 and May 1998 and who are now 5 years of age or older were eligible for this study. All the infants were screened at 6 weeks postnatal age by one of the authors (AM) and treated by another (CJL) under general anaesthesia within $48 \mathrm{~h}$ of recognition of threshold ROP as defined by the Multicenter Trial of Cryotherapy for Retinopathy of Prematurity. ${ }^{1}$

Confluent photocoagulation burns were applied to the nonvascularized retina anterior to the demarcation ridge, and all patients were seen at weekly intervals to ensure regression of the ROP after treatment. An HGM argon laser model 8 was used via indirect delivery at a wavelength of $514.5 \mathrm{~nm}$.

All patients were recalled for a full ophthalmological examination. The best-corrected visual acuity (BCVA) was determined using the Snellen or HVOT letter recognition chart at $20 \mathrm{ft}$. In order to include all the data in the statistical analysis, any eye with no perception of light was assigned a visual acuity of 20/2000. Preferential looking acuities using Teller cards were used for the three patients who could not manage optotype acuities due to cognitive limitations, as shown in Table 1 . The presence of nystagmus was noted. Stereoacuity was assessed with the Titmus test and ocular alignment by cover and prism cover testing. Cyclopentolate $1 \%$ drops were instilled in each eye $30 \mathrm{~min}$ prior to retinoscopy. Indirect fundoscopy was performed with particular attention to the presence of the scarring sequelae of ROP including straightening of the major arcade vessels, macular distortion or dragging, hooding of the optic disc, and tractional retinal detachment. The visual fields were assessed using kinetic perimetry with a $40 \mathrm{~cm}$ arc perimeter, presenting the child a white foam ball of $4 \mathrm{~cm}$ in diameter, which is moved from the periphery towards the fixation target in at least four meridians (left, right, superior and inferiorly), testing each direction at least three times in a random order, as described by van Hof-van Duin et al. ${ }^{17}$

At a separate visit, each patient was seen by a paediatric neurologist (JJ) and/or developmental paediatrician (CM) from the Visual Impairment Program. In addition, patients were evaluated by a trained neuropsychologist using the WISC III-R to determine their intellectual function. ${ }^{18}$ Four patients could not be tested in this way due to significant mental handicap. Patients scoring low-normal or better $(80+)$ would be expected to require less academic support and were therefore considered for the purposes of this study to have a good cognitive outcome. Conversely, those

Table 1 Functional outcome

\begin{tabular}{|c|c|c|c|c|c|c|c|c|c|c|}
\hline \multirow[t]{2}{*}{ Patient } & \multirow[t]{2}{*}{$B W$} & \multirow[t]{2}{*}{$G A$} & \multirow[t]{2}{*}{ Gender } & \multicolumn{2}{|c|}{$B C V A$} & \multicolumn{2}{|c|}{ Spherical equivalent $(D)$} & \multicolumn{2}{|c|}{ Stereoalignment } & \multirow[t]{2}{*}{ VF loss (deg) } \\
\hline & & & & Right & Left & Right & Left & & & \\
\hline 1 & 940 & 26 & M & $20 / 100$ & $20 / 40$ & -16.00 & -10.00 & 0 & Normal & $10-15$ \\
\hline 2 & 1335 & 30 & $\mathrm{~F}$ & $20 / 20$ & $20 / 20$ & -2.75 & -3.12 & 200 & Normal & $<10$ \\
\hline 3 & 728 & 25 & M & $20 / 20$ & $20 / 25$ & +1.00 & +0.75 & 100 & Normal & $<10$ \\
\hline 4 & 1050 & 31 & M & $20 / 20$ & $20 / 20$ & +0.50 & +0.75 & 200 & Normal & 0 \\
\hline 5 & 980 & 26 & $\mathrm{~F}$ & $20 / 20$ & $20 / 20$ & +0.75 & +0.62 & 40 & Normal & NA \\
\hline 6 & 1015 & 26 & $\mathrm{~F}$ & $20 / 30$ & $20 / 25$ & -6.50 & -8.00 & 0 & Normal & $10-15$ \\
\hline 7 & 905 & 25 & $\mathrm{~F}$ & $20 / 20$ & $20 / 25$ & +0.75 & 0.00 & 80 & Normal & $<10$ \\
\hline 8 & 790 & 26 & $\mathrm{~F}$ & $20 / 25$ & $20 / 25$ & -4.00 & -4.00 & 100 & Normal & NA \\
\hline 9 & 855 & 27 & $\mathrm{~F}$ & $20 / 20$ & $20 / 20$ & +0.33 & +0.75 & 60 & Normal & NT \\
\hline 10 & 530 & 23 & $\mathrm{~F}$ & $20 / 20$ & $20 / 20$ & 0.00 & 0.00 & 50 & Normal & $<10$ \\
\hline 11 & 873 & 25 & M & $20 / 50$ & $20 / 60$ & -11.00 & -13.00 & 0 & $\mathrm{ET}$ & $<10$ \\
\hline $12^{\mathrm{a}}$ & 720 & 23.6 & M & $20 / 400$ & Stage 5 & -7.00 & Stage 5 & 0 & ET & $40-50^{\mathrm{b}}$ \\
\hline 13 & 650 & 24 & $\mathrm{~F}$ & $20 / 40$ & $20 / 20$ & -0.50 & +0.62 & 800 & ET & $<10$ \\
\hline $14^{\mathrm{a}}$ & 945 & 26 & $\mathrm{~F}$ & $20 / 80$ & $20 / 80$ & +1.50 & +2.75 & 0 & ET & NT \\
\hline 15 & 565 & 24 & $\mathrm{~F}$ & $20 / 25$ & $20 / 30$ & -6.40 & -2.25 & 100 & normal & 0 \\
\hline 16 & 550 & 24 & $\mathrm{~F}$ & $20 / 30$ & $20 / 40$ & -7.50 & -8.75 & 400 & normal & $<10$ \\
\hline 17 & 670 & 24 & $\mathrm{~F}$ & $20 / 25$ & $20 / 80$ & -8.25 & -10.50 & 0 & ET & 0 \\
\hline 18 & 975 & 26 & M & $20 / 40$ & $20 / 30$ & -11.00 & -10.50 & 100 & normal & NA \\
\hline 19 & 730 & 25 & $\mathrm{~F}$ & $20 / 25$ & $20 / 20$ & -13.50 & -10.00 & 200 & normal & 20 \\
\hline 20 & 735 & 26 & $\mathrm{~F}$ & $20 / 60$ & $20 / 60$ & -7.40 & -6.25 & 3000 & normal & NT \\
\hline $21^{\mathrm{a}}$ & 855 & 27 & $\mathrm{~F}$ & $20 / 200$ & $20 / 200$ & -14.00 & -12.00 & 0 & $\mathrm{HT}$ & $40-50$ \\
\hline
\end{tabular}

$\mathrm{BCVA}=$ Best-corrected visual acuity; $\mathrm{GA}=$ gestational age at birth, in weeks; $\mathrm{BW}=$ birth weight, in grams; $\mathrm{ET}=\mathrm{esotropia} ; \mathrm{HT}=$ hypertropia; $\mathrm{NA}=$ not available; $\mathrm{NT}=$ not testable.

${ }^{a}$ VA determined with Teller acuity cards.

${ }^{\mathrm{b}}$ Tested in only one eye. 
scoring borderline mental handicap or worse were classified as having a poor cognitive outcome. The patients who could not be tested with WISC III-R because of their mental handicap, were classified as poor cognitive outcomes for the purpose of analysis. Pearson's $R$ was used to determine the strength of association between (a) the cognitive level and visual acuity, (b) cerebral palsy (CP) and visual acuity, (c) periventricular leukomalacia (PVL) and visual acuity, and (d) intraventricular haemorrhage (IVH) and visual acuity. In order to allow statistical handling of acuity values, the Snellen acuities were converted to logMAR. Also for statistical purposes, when analysing

neurodevelopmental outcome, visual acuity of 20/40 or better in the best eye was considered a good visual outcome, and visual acuity of less than 20/40 a poor visual outcome.

\section{Results}

Ín total, 23 infants were treated with bilateral argon laser photocoagulation to the peripheral nonvascularized retina between March 1994 and May 1998. Two of these died before the age of 6 months (deaths not related to ROP laser treatment); until that time, their retinas had been recorded to be attached. The information on these two patients was excluded from the analysis, leaving a total of 21 patients (42 eyes) in this study. All these (100\%) were recruited and reviewed. There were 15 female and six male patients whose average chronological age at the time of follow-up was 6.2 years (range: 5-7.6). The mean gestational age at birth was 25.7 weeks (range: $23-35)$ and mean birth weight was $828 \mathrm{~g}$ (range: 530-1335). Of the 42 eyes, 40 (95\%) had had at least 5 contiguous or 8 cumulative clock hours of stage $3+$ disease in zone II at the time of treatment; the two eyes $(5 \%)$ of patient no.12 had zone I rush disease. Laser treatment was performed bilaterally in all cases, at a mean of 34.6 weeks postmenstrual age (range: 31.4-38.2 weeks). Lack of regression of ROP despite treatment was observed in five patients 1 week after the initial treatment, and they underwent repeat laser photocoagulation. In four of these patients, the disease then regressed but in one (patient no. 12) continued progression was noted.

\section{Visual and refractive outcome}

Of the 42 eyes, $30(71 \%)$ achieved a BCVA of $20 / 40$ or better and $14(33 \%)$ a BCVA of 20/20. Overall, the mean visual acuity was $20 / 98$. When the only eye with retinal detachment was excluded, the mean visual acuity in the group was 20/52. This information is summarized in Table 1. Six patients had strabismus $(28.5 \%)$ and three
Table 2 Anatomical outcome

\begin{tabular}{clll}
\hline Patient & $\begin{array}{l}\text { Vascular } \\
\text { straightening }\end{array}$ & $\begin{array}{l}\text { Macular } \\
\text { distortion }\end{array}$ & $\begin{array}{l}\text { Disc } \\
\text { hooding }\end{array}$ \\
\hline 1 & $\mathrm{R}$ & & \\
4 & $\mathrm{RL}$ & & \\
9 & $\mathrm{RL}$ & $\mathrm{RL}$ & $\mathrm{RL}$ \\
11 & $\mathrm{RL}$ & $\mathrm{R}$ & $\mathrm{R}$ \\
$12^{\mathrm{a}}$ & $\mathrm{R}$ & & \\
14 & $\mathrm{RL}$ & $\mathrm{R}$ & \\
18 & $\mathrm{RL}$ & $\mathrm{R}$ & \\
20 & $\mathrm{R}$ & & \\
21 & $\mathrm{R}$ & & \\
\hline
\end{tabular}

$\mathrm{R}=$ right eye; $\mathrm{RL}=$ both eyes.

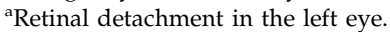

nystagmus (14.3\%). Four patients were treated for amblyopia. In three of them, anisometropia and strabismus were present, and in one other, only strabismus was present. Stereopsis was present in 14 patients $(66.6 \%)$.

The overall average refractive spherical equivalent (SE) after laser photocoagulation was $-4.95 \mathrm{D}$ (range:-16.0 to $+2.75)$. Of the 42 eyes, 26 (62\%) were myopic, $20(47.6 \%)$ with a spherical equivalent greater than $-4.0 \mathrm{D}$. The refractive outcome is shown in Table 1 . The astigmatism ranged from 0 to $3.5 \mathrm{D}$ (mean $2.0 \mathrm{D}$ ). In all, 26 eyes $(62 \%)$ had with-the-rule astigmatism and only one eye $(2.4 \%)$ against-the-rule. Two patients had a difference greater than $1 \mathrm{D}$ between the degree of astigmatism of their eyes.

Visual fields were available in 29 eyes of 15 patients. In $24(83 \%)$ eyes, the reduction of visual field was minimal, in the order of $15^{\circ}$ or less. Individual visual field results are also presented in Table 1.

\section{Anatomical outcome}

Of the 42 treated eyes, one progressed to stage 5 ROP despite treatment $(2.4 \%)$. None of the treated eyes had stage 4 findings or macular folds at follow-up. Some degree of macular distortion was seen in four eyes. The anatomical outcome is summarized in Table 2.

\section{Neurodevelopmental outcome}

Neurological problems were common in this series; of 21 patients, 13 had IVH (62\%), seven CP $(33.3 \%)$, and five PVL (23.8\%). Of these disorders, CP was the most likely to be associated with poor visual outcome as described above, although this was not invariably the case. Three out of $16(19 \%)$ children with good visual outcome had $\mathrm{CP}$, compared to four out of five $(80 \%)$ who had a poor visual outcome $(P=0.009)$. IVH was also associated with poor vision, since all the five children with poor visual outcome (100\%) had IVH, compared to eight of 16 (50\%) 
Table 3 Neurodevelopmental outcome

\begin{tabular}{lccc}
\hline Visual acuity & \multicolumn{3}{c}{ Cognitive outcome } \\
\cline { 2 - 4 } & Good & Poor & Total \\
\hline$\geqslant 20 / 40$ & 10 & 6 & 16 \\
$<20 / 40$ & 0 & 5 & 5 \\
Total & 10 & 11 & 21 \\
\hline
\end{tabular}

with good visual outcome $(P=0.047)$. Three out of 16 (19\%) children with good visual outcome had PVL, compared to two out of five children $(40 \%)$ with poor visual outcome $(P=0.35)$.

In addition, psychoeducational testing documented 11 children who scored in the borderline range $(\mathrm{IQ}<80)$ or worse, and Pearson's $R$ demonstrated an association between poor cognitive outcome as defined above and visual acuity worse than $20 / 40(P=0.013)$. See Table 3.

\section{Discussion}

The Cryo-ROP study showed the beneficial effect of treatment on visual acuity and anatomic status at 10 years follow-up. ${ }^{19}$ Laser photocoagulation has replaced cryotherapy as the standard treatment in most centres. The diode laser is now also widely used, although the outcome of this modality is not considered by this study. More recently, threshold criteria for treatment have been re-evaluated. ${ }^{20}$ However, few studies of long-term outcome after laser treatment are available: Two of the 23 eyes treated with laser by $\mathrm{Ng}$ et al, had developed stage 5 ROP at 10-year follow-up evaluation. ${ }^{5}$ Shalev et $a l^{21}$ followed up 10 eyes treated with laser for ROP for 7 years; none of these developed stage $5 \mathrm{ROP}$ although one patient who had an unfavourable outcome in the laser treated eye died before follow-up. In our study, only one eye of $42(2.4 \%)$ developed a total retinal detachment. Although two infants died before the age of 6 months and were therefore excluded from the study, neither had retinal detachment prior to their death. Other authors have reported favourable structural outcomes as defined by the Cryo-ROP study after laser treatment, with shorter follow-up times. ${ }^{9,22-25}$

It is interesting to note that the only child who developed stage 5 ROP in our series had documented progression of severe rush disease in zone I despite two sets of laser photocoagulation to each eye. Only one of his eyes was judged by the vitreoretinal surgeon to have visual potential and therefore underwent vitrectomy. At follow-up, this eye had become phthisical; the contralateral (unoperated) eye retained a flat but severely distorted retina with a visual acuity of $20 / 400$. In the
Cryo-ROP study, disease in zone II resulted in fewer unfavourable outcomes in both treated and control eyes than zone I disease. . $^{2,3}$ The severity and posterior location of the disease in the eye that developed stage 5 in our series likely contributed to the poor outcome. Macular ectopia was, as expected, a factor contributing to poor visual outcomes in patients 11, 12, and 20 in our series.

A high prevalence of myopia has been reported in premature babies. ${ }^{26-29}$ Prematurity in the absence of ROP has also been associated with a higher prevalence of myopia. ${ }^{29-31}$ Previous studies have found a positive correlation between myopia and more severe degrees of $\mathrm{ROP}_{1}^{27,32,33}$ and $\mathrm{O}^{\prime}$ Connor $e t \mathrm{al}^{30}$ reported that the prevalence of myopia in prematurely born children reexamined at 10-12 years of age increased from $22 \%$ in those with no ROP to $80 \%$ in those with ROP stage $3 / 4$. Children with stage 1 and 2 disease did not differ from those with no ROP. Several authors have reported lower degrees of myopia after laser than cryotherapy treatment. ${ }^{7,8,10-12,34}$ Myopia was present in $62 \%$ of eyes in our series; the mean spherical equivalent of our patients $(-4.95 \mathrm{D})$ was similar to that found in other series of children older than 3 years, in which the mean ranged from -3.05 to $-6.5 \mathrm{D}^{7,8,21,35}$

The Cryo-ROP study showed that $44 \%$ of eyes treated had vision of 20/200 or worse at 10-year follow-up, compared to $62.1 \%$ of eyes that were not treated. The same study reported visual acuity of $20 / 40$ or better in $25.2 \%$ of treated vs $23.71 \%$ of nontreated eyes. ${ }^{19}$ Smaller comparative studies have found good visual outcomes in the group of eyes treated with laser.9, ${ }^{91}$ An overall mean visual acuity of 20/98 in 42 eyes of our study constitutes functional success, particularly because 30 eyes $(71 \%)$ achieved final vision of $20 / 40$ or more and 14 eyes (33\%) saw 20/20 at follow-up. The mean age of patients in this study was slightly lower than in the Cryo-ROP study, possibly reflecting the fact that neonatal care has improved since that study was done.

A reduction of $5-7^{\circ}$ in the peripheral visual field was reported at the 10-year examination of the treated Cryo-ROP patients. ${ }^{36}$ Laser photocoagulation of both peripheral retinas to mid- or posterior zone II, as was necessary in some of the patients in this study, would be expected to cause significant peripheral visual field restriction; visual fields were only available in 29 of the 42 eyes in this study and formal testing using the Goldmann perimeter was not attempted due to the patients' young age. Nevertheless, in 24 eyes the visual field reduction was subtle, judged to be in the order of $15^{\circ}$ or less. We felt overall that it did not impact function significantly.

Infants with extremely low birth weight are at risk of neurological abnormalities, developmental and functional delay. ${ }^{37} \mathrm{~A}$ child's visual function is the result 
not only of their visual acuity, field, and eye movements but also their cognitive level, motor skills and other factors. Msall et $a l^{38}$ examined the relationship between ROP and the subsequent neurodevelopmental function in patients from the Cryo-ROP study at age 5.5 years. They found that disability increased from 3.7\% among patients with no ROP, to $19.7 \%$ in those with threshold ROP, and identified ROP as a marker for disability. We focused our assessment on intellectual performance and the presence of neurological factors related to prematurity. We evaluated the cognitive level by determining the intellectual function, and found an association between poor visual outcome and the presence of cognitive impairment. Recently, Cooke et $a l^{39}$ have reported the outcome of a cohort of children whom they have followed since 1991-1992. In their study, the eight children with stage 3 ROP had poorer scores on the Movement ABC and total and verbal IQ, but these differences were of borderline significance after standardizing for gestational age. They suggest a trend which would indicate stage 3 ROP to be a marker for adverse development. Although our study of 21 patients with stage 3 ROP lacked a control group, 11 children had a cognitive handicap (IQ < 80) and seven had CP.

The significance of IVH for long-term visual morbidity has been highlighted by previous studies ${ }^{40,41}$ and Lanzi et $a l^{42}$ found that visual impairment correlated with MRI findings of PVL in children affected by CP. We found that IVH and CP were associated with poor visual outcomes in the study group. In our series, only five patients were found to have PVL, and its presence was not significantly associated with decreased vision, although this could be due to the small numbers in the sample. While we realize that converting Snellen acuities to $\log$ MAR is an approximation, this was necessary to allow statistical analysis of our neurodevelopmental findings.

The results of this study show that at age 5 or above, patients who received confluent retinal argon laser photocoagulation for proliferative ROP have a satisfactory visual outcome since over three-quarters of them $(76.19 \%)$ have binocular vision of $20 / 40$ or better. Myopia is frequent. Laser therapy is effective in achieving a good structural outcome, with only one eye progressing to stage 5 disease. Although a poor visual outcome is sometimes due to retinal distortion, scarring or detachment due to the progression of ROP, this complication is becoming less frequent, accounting for five eyes of three children in this series. Some patients did not achieve good vision despite a good anatomical outcome. Their limited visual outcome was attributed to PVL in two patients (nos. 14 and 21), and unilateral amblyopia two patients (nos. 1 and 17). As a cause of visual morbidity, these factors are now almost as frequent as the scarring sequelae of ROP.

\section{References}

1 Cryotherapy for Retinopathy of Prematurity Cooperative Group. Multicenter trial of cryotherapy for retinopathy of prematurity. Preliminary results. Arch Ophthalmol 1988; 106: 471-479.

2 Cryotherapy for Retinopathy of Prematurity Cooperative Group. Multicenter trial of cryotherapy for retinopathy of prematurity: one-year outcome-structure and function. Arch Ophthalmol 1990; 108: 1408-1416.

3 Cryotherapy for Retinopathy of Prematurity Cooperative Group. Multicenter trial of cryotherapy for retinopathy of prematurity: 3 1/2-year outcome-structure and function Arch Ophthalmol 1993; 111: 339-344.

4 Cryotherapy for Retinopathy of Prematurity Cooperative Group. Multicenter trial of cryotherapy for retinopathy of prematurity. Snellen's visual acuity and structural outcome at $51 / 2$ years after randomization. Arch Ophthalmol 1996; 114: $417-424$

$5 \mathrm{Ng} \mathrm{E}$, Connolly BP, Mc Namara A, Regillo CD, Vander JF, Tasman W. A comparison of laser photocoagulation with cryotherapy for threshold retinopathy of prematurity at 10 years. Part 1. Visual function and structural outcome. Ophthalmology 2002; 109: 928-934.

6 Paysse EA, Lindsey JL, Coats DK, Contant Jr CF, Steinkuller PG. Therapeutic outcomes of cryotherapy versus transpupillary diode laser for threshold retinopathy of prematurity. J AAPOS 1999; 3: 234-240.

7 Connolly BP, McNamara JA, Sharma S, Regillo CD, Tasman $\mathrm{W}$. A comparison of laser photocoagulation with transscleral cryotherapy in the treatment of threshold retinopathy of prematurity. Ophthalmology 1998; 105: 1628-1631.

8 Connolly BP, Ng EY, McNamara JA, Vander JF, Tasman W. A comparison of laser photocoagulation with cryotherapy for threshold retinopathy of prematurity at 10 years. Part 2 . Refractive outcome. Ophthalmology 2002; 109: 936-941.

9 White J, Repka MX. Randomized comparison of diode laser photocoagulation versus cryotherapy for threshold retinopathy of prematurity: 3-year Outcome. J Pediatr Ophthalmol Strabismus. 1997; 34: 83-87.

10 Laws F, Laws D, Clark D. Cryotherapy and laser treatment for acute retinopathy of prematurity: refractive outcomes, a longitudinal study. Br J Ophthalmol 1997; 81: 12-15.

11 Knight-Nanan DM, O'Keefe M. Refractive outcome in eyes with retinopathy of prematurity treated with cryotherapy or diode laser: 3 year follow up. Br J Ophthalmol 1996; 80: 998-1001.

12 Algawi K, Goggin M, O'Keefe M. Refractive outcome following diode laser versus cryotherapy for eyes with retinopathy of prematurity. Br J Ophthalmol 1994; 78: 612-614.

13 Steinkuller PG, Du L, Gilbert C, Foster A, Collins ML, Coats DK. Childhood blindness. J AAPOS 1999; 3: 26-32.

14 Hoyt CS, Good WV. The many challenges of childhood blindness. Br J Ophthalmol 2001; 85: 1145-1146.

15 World Health Organization. Control of major blinding diseases and disorders (2). Fact Sheet \# 214. Reviewed February 2000.

16 Good WV, Gendron RL. Retinopathy of prematurity. Ophthalmol Clin North Am 2001; 14: 513-519.

17 Van Hof-van Duin J, Heersema DJ, Groenendaal F, Baerts W, Fetter WP. Visual field and grating acuity development in 
low-risk preterm infants during the first $21 / 2$ years after term. Behav Brain Res 1992; 31: 115-122.

18 Wechsler D. Manual WISC III: Wechsler Intelligence Scale for Children, 3rd ed. Psychology Corporation: San Antonio, TX, 1991.

19 Cryotherapy for Retinopathy Prematurity Cooperative Group. Multicenter trial of cryotherapy for retinopathy of prematurity. Ophthalmological outcomes at 10 years. Arch Ophthalmol 2001; 119: 1110-1118.

20 Early Treatment for Retinopathy of Prematurity Cooperative Group. Revised Indications for the Treatment of Retinopathy of Prematurity: Results of the Early Treatment for Retinopathy of Prematurity Randomized Trial. Arch Ophthalmol 2003; 121: 1684-1694.

21 Shalev B, Farr AK, Repka MX. Randomized comparison of diode laser photocoagulation versus cryotherapy for retinopathy of prematurity: seven-year outcome. $A m \mathrm{~J}$ Ophthalmol 2001; 132: 76-80.

22 Goggin M, O'Keefe M. Diode laser for retinopathy of prematurity - early outcome. Br J Ophthalmol 1993; 77: 559-562.

23 Seiberth V, Linderkamp O, Vardali I, Knorz MC, Liesenhoff H. Diode laser photocoagulation for stage $3+$ retinopathy of prematurity. Graefe's Arch Clin Exp Ophthalmol 1995; 233: 489-493.

24 DeJonge MH, Ferrone PJ, Trese MT. Diode laser ablation for threshold retinopathy of prematurity. Short-term structural outcome. Arch Ophthalmol 2000; 118: 365-367.

25 Foroozan R, Connolly BP, Tasman WS. Outcomes after laser therapy for threshold retinopathy of prematurity. Ophthalmology 2001; 108: 1644-1646.

26 Robinson R, O'Keefe M. Follow-up study on premature infants with and without retinopathy of prematurity. $\mathrm{Br} J$ Ophthalmol 1993; 77: 91-94.

27 Quinn GE, Dobson V, Repka MX, Reynolds J, Kivlin J, Davis $\mathrm{B}$ et al. Development of myopia in infants with birth weights less than 1251 grams. The cryotherapy for retinopathy of prematurity group. Ophthalmology 1992; 99: 329-340.

28 Choi MY, Park IK, Yu YS. Long term refractive outcome in eyes of preterm infants with and without retinopathy of prematurity: comparison of keratometric value, axial length, anterior chamber depth, and lens thickness. Br J Ophthalmol 2000; 84: 138-143.

29 Larsson EK, Rydberg AC, Holmstrom GE. A populationbased study of the refractive outcome in 10-year-old preterm and full-term children. Arch Ophthalmol 2003; 121: 1430-1436.

30 O'Connor AR, Stephenson T, Johnson A, Tobin MJ, Moseley $\mathrm{MJ}$, Ratib $\mathrm{S}$ et al. Long-term ophthalmic outcome of low birth weight children with and without retinopathy of prematurity. Pediatrics 2002; 109: 12-18.

31 Fledelius HC. Pre-term delivery and subsequent ocular development. A 7-10 year follow-up of children screened 1982-84 for ROP. (3) Refraction. Myopia of prematurity. Acta Ophthalmol Scand 1996; 74: 297-300.

32 Laws D, Shaw DE, Robinson J, Jones HS, Ng YK, Fielder AR. Retinopathy of prematurity: a prospective study. Review at six months. Eye 1992; 6: 477-483.

33 Quinn GE, Dobson V, Kivlin J, Kaufman LM, Repka MX, Reynolds JD et al. Prevalence of myopia between 3 months and $51 / 2$ years in preterm infants with and without retinopathy of prematurity. Ophthalmology 1998; 105: 1292-1300.

34 Kent D, Pennie F, Laws D, White S, Clark D. The influence of retinopathy of prematurity on ocular growth. Eye 2000; 14: 23-29.

35 Connolly BP, McNamara JA, Regillo CD, Tasman W, Sharma $\mathrm{S}$. Visual outcomes after laser photocoagulation for threshold retinopathy of prematurity. Ophthalmology 1999; 106: $1734-1737$.

36 Cryotherapy for Retinopathy of Prematurity Cooperative Group. Effect of retinal ablative therapy for threshold retinopathy of prematurity. Results of Goldman perimetry at the age of 10 years. Arch Ophthalmol 2001; 149: 1120-1124.

37 Vohr BR, Wright LL, Dusick AM, Mele L, Verter J, Steichen JJ et al. Neurodevelopmental and functional outcomes of extremely low birth weight infants in the National Institute of Child Health and Human Development Neonatal Research Network, 1993-1994. Pediatrics 2000; 105: 1216-1226.

38 Msall ME, Phelps DL, DiGaudio KM, Dobson V, Tung B, McClead RE et al. Severity of neonatal retinopathy of prematurity is predictive of neurodevelopmental functional outcome at age 5.5 years. Pediatrics 2000; 106: 998-1005.

39 Cooke RW, Foulder-Hughes L, Newsham D, Clarke D. Ophthalmic impairment at 7 years of age in children born very preterm. Arch Dis Child Fetal Neonatal Ed 2004; 89: F249-F253.

40 Holmstrom G, el Azazi M, Kugelberg U. Ophthalmological follow up of preterm infants. A population based, prospective study of visual acuity and strabismus. $\mathrm{Br} \mathrm{J}$ Ophthalmol 1999; 83: 143-150.

41 O'Keefe M, Kafil-Hussain N, Flitcroft I, Lanigan B. Ocular significance of intraventricular hemorrhage in premature infants. Br J Ophthalmol 2001; 85: 357-359.

42 Lanzi G, Fazzi E, Uggetti C, Cavallini A, Danova S, Egitto MG et al. Cerebral visual impairment in periventricular leukomalacia. Neuropediatrics 1998; 29: 145-150. 